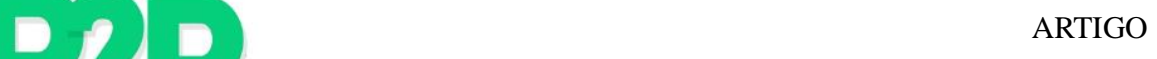

\title{
REDES COLABORATIVAS E PENSAMENTO P2P: a dobra brasileira
}

\section{Ivana Bentes}

Professora do Programa de Pós Graduação em Comunicação da ECO/UFRJ, coordenadora do Pontão de Cultura Digital da ECO/UFRJ.

Parte desse texto foi publicado em:

BENTES, Ivana. Redes colaborativas e o precariado produtivo: Le Monde Diplomatique: caminhos para uma comunicação democrática, São Paulo, v. 2, n. 1, p.1-22, 2007.

\begin{abstract}
Resumo
Apresenta um panorama dos movimentos socioculturais que ganham dimensão política ao serem portadores de expressões culturais e estilos de vida vindos da periferia. Descreve a experiência da cultura a partir dos movimentos socioculturais que surgem como possibilidades de uma renovação radical das políticas públicas. Estabelece que o peer to peer (P2P), considerado ponto a ponto, é o modelo de funcionamento de novos processos sociais que, consequentemente, faz surgir um terceiro modo de produção, de autoridade e de propriedade e visam aumentar a participação generalizada de atores equipotenciais.
\end{abstract}

\section{Palavras-chave}

Redes colaborativas. Peer to peer. Futuros alternativos.

\begin{abstract}
It presents an overview of the socio-cultural movements that get political dimension when they have cultural expressions and lifestyles coming from the periphery. It describes the experience of culture from the socio-cultural movements that arise as possibilities of a radical overhaul of public policy. It establishes that the peer to peer (P2P), also known as point to point, is the working model of new social processes that consequently makes a third mode of production, authority and ownership and also increase the widespread participation of equipotential actors.
\end{abstract}

\section{Keywords}

Collaborative networks. Peer to peer. Alternative futures.

\section{INTRODUÇÃO}

Vivemos um momento singular e de mudança de eixo na produção cultural contemporânea com a ascensão e visibilidade da produção cultural vinda das periferias, subúrbios e favelas. Uma produção cultural deslocada, lateral que traz consigo embriões de políticas públicas potenciais, com a possibilidade de redistribuição de riqueza e de poder, se constituindo também como lugar de trabalho vivo e não meramente reprodutivo.

Essa cultura das favelas e periferias (música, teatro, dança, literatura, cinema), surge como um discurso político "fora de lugar" (não vem da universidade, não vem do Estado, não vem da mídia, não vem de partido político) e coloca em cena novos mediadores e produtores de cultura: rappers, funkeiros, b-boys, jovens atores, performers, favelados, desempregados, sub-empregados, produtores da chamada economia informal, grupos e discursos que vêm revitalizando os territórios da pobreza e reconfigurando a cena cultural urbana. Transitam pela cidade e ascendem à mídia de forma muitas vezes ambígua, podendo assumir esse lugar de um discurso político urgente e de renovação num capitalismo da informação. 
A mudança decisiva se dá a partir do contexto em que estamos, onde os meios de produção cultural se disseminam e os meios de comunicação e informação estão sendo massificados. Internet, câmeras digitais, celular, impressoras, servem a quem quer se tornar produtor de cultura.

Esse contexto de um capitalismo informacional, capitalismo cognitivo, onde o conhecimento é o produto, chega a todos os meios sociais e também na favela, mesmo que de forma desigual e assimétrica. Um jovem na favela e periferia recebe através da TV aberta, e a cabo, da música, das novas formas de socialibilidade, uma informação e formação geral que vai constituindo uma inteligência de massas, inteligência coletiva em desenvolvimento acelerado.

Esses movimentos sócio-culturais ganham uma dimensão política ao serem portadores de expressões culturais e estilos de vida vindos da pobreza, forjadas na passagem de uma cultura letrada para uma cultura audiovisual e midiática.

A cultura das favelas e periferias também é um contraponto para a visão estereotipada das favelas como fábricas de morte e violência, aspecto recorrente na mídia e no cinema que revela apenas a imagem da favelainferno, território a pulsão de morte, sem olhos para a cultura de resistência e vitalidade que vem sendo forjada aí e sua relação com novas formas de trabalho e ocupação.

A complexidade e ambiguidade da "dobra" brasileira no capitalismo global vem mostrando que as fábricas de pobreza e violência são também territórios e redes de criação. Essas vozes da periferia, jovens artistas e agitadores, negros saídos da favela, de ambientes de violência e hostilidade destituem os tradicionais mediadores da cultura, passam de "objetos" a sujeitos do discurso, contribuindo com uma renovação do político, e com os discursos mais contundentes sobre racismo, violência policial e pobreza, concorrendo com os discursos da universidade e da mídia.

Nas favelas e periferias produziram-se novas relações de vizinhança, mutirões, redes de ajuda rizomáticas, a cultura das festas, rituais religiosos, samba, funk, hip-hop, todo um capital cultural e afetivo forjadas num ambiente de brutalidade compartilhado por diferentes grupos sociais. Das favelas e periferias surgem práticas de cultura, estéticas e redes de sociabilidade e política forjadas dentro dos guetos, mas conectadas aos fluxos globais (não é só o tráfico de drogas que consegue se globalizar) até a mídia já consegue enxergar esse novo contexto.

Grupos e territórios locais apontando saídas possíveis, rompendo com o velho "nacional-popular" populista e paternalista ou ideias engessadas de "identidade nacional", e surgindo como expressões de um gueto global, dos guetos-mundo. Como é falado hoje de cidades globais, com questões e problemas comuns. O novo produtor de cultura das favelas e periferias faz parte de um precariado global, são os produtores sem salário nem emprego. São os trabalhadores do imaterial.

Estamos vendo surgir também novas alianças entre as favelas e grupos antes isolados, a ideia de constituição de redes, inclusive eletrônicas, pode ser a próxima etapa nesse salto dos movimentos culturais locais e globais. Cidades da cooperação que rivalizam com o Estado Nação, e funcionam a revelia dele. Uma política inteligente de governo deve necessariamente incluir essas experiências culturais que se constituíram de forma rizomática, vitalizando periferias e centros, afastando-se do impulso meramente assistencialista e paternalista e afirmando essa "qualidade" político-estética conquistada pelos movimentos culturais.

Movimentos que surgem na crise do Estado como provedor, com base na sociedade salarial em que transferência de renda apenas, não acaba com as desigualdades. Como dar suporte a essas redes socioculturais? 
Estamos vivendo uma reestruturação produtiva, e na cultura isso é claro, a cultura é hoje o lugar do trabalho informal (não assalariado), com o primado do trabalho imaterial, grupos, redes, movimentos que trabalham com informação, comunicação, arte, conhecimento e que não estão nas grandes corporações. Seria preciso pensar novas agendas estratégicas, sem as forças imediatistas do mercado, nem as decisões centralizadas demais do Estado. Uma radicalização da democracia estimulando a produtividade social.

Essa experiência da cultura a partir dos movimentos socioculturais surge como possibilidades de uma renovação radical das políticas públicas. Não é só uma mudança da política para a cultura, mas uma mudança da própria cultura política. São muitas iniciativas com potencial para serem instituídas e o Brasil surge como laboratório desses projetos culturais.

Podemos destacar, entre outros, economia e cultura do funk e do hip hop, movimentos que produzem novas identidades e sentimento de pertencimento, de comunidade, para além da música e criam mundos e atividades produtivas: djs, donos de equipamentos de som, donos de vãs, organizadores de bailes, seguranças e rappers, funkeiros que fazem até dez apresentações em bailes diferentes numa única noite. Todo um ciclo econômico em torno da cultura hip hop e funk que explicita o primado da cultura na constituição da economia cognitiva do capitalismo contemporâneo.

Essas redes culturais locais se constituem em contrastes com as políticas públicas organizadas do centro, super hierarquizadas, centralizadas, e que não resolveram ou reduziram a um nível desejável as desigualdades sociais. Hoje nós temos uma oportunidade histórica de experimentar outros modelos de políticas públicas, ainda embrionários, redes socioculturais, que funcionam justamente de forma horizontal, acentrada, rizomática, organizando a própria produção.

Os movimentos culturais trabalham com uma ideia de educação não formal, como porta de entrada para a educação formal e para o trabalho vivo. Um movimento como o MST conseguiu construir escolas e propor programas educativos com mais rapidez que muitas prefeituras no interior do país. A produção cultural da periferia também não é formal, é precária, informal, veloz, e se dá em redes, colaborativas, produzindo transferência de capital simbólico e real, poder para os movimentos socioculturais, sem os tradicionais mediadores culturais e de poder.

Esses movimentos sociais tornam-se habilitados a administrar a própria cultura que produzem, ao mesmo tempo podem ser parceiros significativos de quem detém os meios de produção, difusão, etc. Os movimentos socioculturais podem atuar em todas as pontas: como produtores de cultura, administradores e beneficiários do resultado da sua produção.

Se os atores culturais e sociais dispõem de recursos intelectuais e materiais para assumirem esse protagonismo, qual o papel das políticas públicas? Apoiar, estimular e promover, formar lideranças, agentes de cultura, administradores de cultura, de eventos culturais, dar as condições mínimas para esse desenvolvimento.

\section{REDES COLABORATIVAS E O MODELO P2P}

Nunca na história da cultura tivemos tantas possibilidades de descentralização dos meios de produção. Equipamentos digitais, câmeras de vídeo, câmeras fotográficas, equipamentos para músicos, djs, produtores de audiovisual, computadores pessoais, softwares livres, uma enorme capacidade em duplicação de cds, livros, música 
que colocam em xeque o direito autoral tradicional e fazem vislumbrar um capitalismo do excedente e da possibilidade da livre circulação do conhecimento. Quais as bases “tecnológicas” dessas mudanças?

Segundo Michel Bauwens, em “A Economia Política da Produção entre Pares"1, à medida que os sistemas sociais, econômicos e políticos se transformam em redes distribuídas, surge uma nova dinâmica produtiva: o modelo peer to peer (P2P), ponto a ponto. Mais que uma nova tecnologia de comunicação é o modelo de funcionamento de novos processos sociais e faz surgir um terceiro modo de produção, de autoridade e de propriedade e visam aumentar a participação generalizada de atores equipotenciais. Suas características mais importantes, segundo Michel Bauwens, que encontramos nas experiências das redes colaborativas brasileiras e coletivos são:

1) Produção de valor de uso através da cooperação livre entre produtores que têm acesso a capital distribuído. O seu produto não reside num valor de troca destinado ao mercado, mas num valor de uso dirigido a uma comunidade de utilizadores.

2) Administração pela comunidade de produtores e não por mecanismos de alocação do mercado ou por uma hierarquia empresarial. Este é o modo de autoridade P2P ou "terceiro modo de autoridade".

3) Disponibilizar livremente o valor de uso segundo um princípio de universalidade, através de novos regimes de propriedade comum. Este é o seu "modo de propriedade distribuída ou entre pares", diferente da propriedade privada ou da propriedade pública, estatal.

A infraestrutura do P2P e Redes Sociais Colaborativas têm algumas condições básicas, propostas por Bauwens, necessárias para facilitar a emergência de processos entre pares, que podemos resumir, como:

A existência de uma infraestrutura tecnológica instalada. Os movimentos para a inclusão digital, com a disseminação de computadores pessoais e coletivos, acesso público a internet e das redes comunitárias sem fios e em defesa do espectro aberto, os sistemas televisivos de file-serving - TiVo - e as infraestruturas alternativas de telecomunicação baseadas em meshworks são representativos desta tendência.

Sistemas alternativos de informação e comunicação que permitam a comunicação autônoma entre agentes cooperantes. A Web (em particular, a Writable Web e a Web 2.0) permitem a produção, disseminação e "consumo" do material escrito, assim como o podcasting e o webcasting criam uma infraestrutura alternativa de informação e comunicação multimídia sem o intermédio dos meios de comunicação clássicos (embora possam vir a surgir novas formas de mediação).

O terceiro requisito é a existência de uma infraestrutura de "software" destinada à cooperação autônoma global. Um número crescente de ferramentas de colaboração que se inserem nos softwares de redes sociais, tais como os blogs e as wikis, facilita a criação de confiança e capital social, permitindo a criação de grupos globais que conseguem criar valor de uso sem o intermédio da produção ou distribuição efetuada por organizações com fins lucrativos.

O quarto requisito é uma infraestrutura legal que permita a criação de valor de uso e que o proteja da apropriação privada. A General Public Licence (que proíbe a apropriação do código de software), a análoga Open Source Initiative e certas versões da licença Creative Commons desempenham esta função. Elas possibilitam a

1 The Political Economy of Peer Production em http://www.ctheory.net/articles.aspx?id=499 e em www.p2pfoundation.net/) 
proteção do valor de uso comum e empregam métodos virais para se disseminar. A GPL e outras licenças semelhantes só podem ser utilizadas em projetos que, em troca, coloquem o seu código-fonte adaptado no domínio público.

E finalmente, o requisito cultural. Para Bauwens, assim como para Antonio Negri, Maurizio Lazzarato e os teóricos do Capitalismo Cognitivo, esse requisito aponta para a difusão da intelectualidade de massa, ou seja, a distribuição da inteligência humana, com as transformações nas formas de sentir e ser (ontologia), nas formas de conhecer (epistemologia), e em valores que contribuem para a criação de um "individualismo cooperativo", uma das novas bases das redes colaborativas.

A estas proposições de Bauwens podemos acrescentar a dobra brasileira. Como enfrentar essa questão de uma outra forma que não criminalizando o produtor e consumidor de bens culturais? Pois se um camelô vende cd duplicado, dvd duplicado de musica, de filme, se ele vende na porta do show de funk o que o garoto acabou de ouvir e dançar e quer levar pra casa, será que o papel do Estado e das Corporações é criminalizar esse consumidor, criador, propagador, esse agente de difusão virótica de cultura que virou o camelô, os adolescentes, as videolocadoras, os cineclubes, coletivos, blogueiros, as comunidades de troca de softwares os produtores e consumidores de cultura locais e globais?

Ao invés de reprimir, como legalizar “a cultura popular digital” (Hermano Vianna) que está se formando? Que não é só a questão da pirataria, é a oportunidade de um grupo de hip hop ou de funk formar sua equipe de som, tocar na favela, nas comunidades, nos clubes, gravar sua música, queimar o seu cd e vender na porta do baile, formando uma rede produtiva que dá trabalho, ocupação e sentido para uma vida.

Hoje, um computador pessoal de baixo custo e acesso à internet são bens culturais essenciais no capitalismo cognitivo, pois o trabalho se tornou comunicacional e relacional. O desafio é como universalizar e socializar esses meios de produção de comunicação que são os meios de produção de cultura. Se apenas 10\% da população brasileira tem computador em casa, então tem que ter uma bolsa cultura, bolsa comunicação, bolsa informática e colocar um computador funcionando em cada casa, centro, associação de moradores, quiosques públicos. Pois comunicação e cultura se tornaram estratégicos para a sociedade civil. Nesse sentido um dos programas mais significativos do governo Lula são os Pontos de Cultura, implementados pelo Ministério da Cultura em todo o país.

É preciso reconhecer a dimensão produtiva desses movimentos que não devem receber bolsas com contrapartidas, mas bolsas-investimentos, pois eles próprios já são a contrapartida (Giuseppe Cocco), são os agentes produtivos que estão transformando realidades locais, são modelos embrionários de transformação radical das políticas públicas. São eles que produzem cultura a partir do local, vivem e moram em territórios abandonados e revitalizados de dentro.

Também podemos falar da crise e extinção da tutela intelectual, econômica sobre os movimentos que desconfiam das relações assimétricas e do roubo de capital simbólico e de um valor e um bem altamente valorado no contexto contemporâneo, a produção de mundos. Dessa forma, é a universidade, é a mídia, é o marketing social, ou o que eu chamo de "a lavagem social" que precisa das periferias para se legitimar socialmente, intelectualmente ou até economicamente.

Os exemplos são muitos. A Companhia de Teatro Nós do Morro, que transformou meninos da favela em atores, com uma formação rigorosa que inclui uma formação profissional em várias áreas co-relatas, teatro, cinema, 
video, técnico de luz, produtor de cultura; criando uma oportunidade para os atores vindos das periferias entrarem na Globo, no cinema, estrelarem filmes como Cidade de Deus, ou simplesmente se tornarem técnicos da indústria cultural.

A Companhia Étnica de Dança, levou a dança contemporânea ao morro do Andaraí e montou uma escola de dança e educação não formal que forma não só dançarinos, mas produtores culturais, iluminadores, coreógrafos, administradores de projetos, e abriu uma oportunidade de qualificar garotos que não necessariamente vão virar bailarinos profissionais, junto com uma formação que inclui discussão sobre racismo, violência, sexualidade, temas trazidos pelos alunos. A Cia Étnica de Dança administra uma escola de samba, do Andaraí que vira escola de cidadania ensinando atividades e ocupações em um mercado da cultura, que é tanto informal e precário quanto formal e instituído.

O trabalho estético e político do grupo Afroreggae consegue tirar os meninos do tráfico para atuarem como músicos, coordenadores de projetos, performers, atores de circo, administradores de projetos. O Afroreggae é um grupo que atua na zona de combate, na "faixa de Gaza" que divide duas favelas, a Maré e o Complexo do Alemão, funcionando como instância mediadora que impede mortes, negocia paz, isso a partir de um status conquistado com o trabalho cultural. O Afroreggae se estende para projetos como o Juventude Polícia, em Minas Gerais, de formação cultural para policiais que se tornam percussionistas. A apresentação conjunta de policiais com o Afroreggae num show de percussão faz uma reversão simbólica importante e reverte a imagem da polícia, de violência, arbítrio, numa potência de sociabilidade e trabalho colaborativo e lúdico.

O trabalho de Jailson de Souza, na Maré, montando um observatório das favelas e produzindo imagens das favelas e uma Escola Crítica de Comunicação Popular que concorre com a fabricação de discursos sobre as favelas; a Coopa Roca da favela da Rocinha, uma bem sucedida cooperativa de artesania e moda produzindo em escala industrial por uma cooperativa de costureiras da favela da Rocinha. O projeto Célula Urbana, levando a Bauhaus alemã para interagir dentro da favela do Jacarezinho, com soluções de arquitetura híbridas. As rádios comunitárias e televisões comunitárias; a rádio Favela de Minas Gerais e Rádio Bicuda do Rio de Janeiro, mídias comunitárias atuantes; a Tv Tagarela da Rocinha são projetos embrionários de uma mídia alternativa.

Todos estes e tantos outros são grupos vitais no delineamento de outra política pública em que os movimentos sociais apontam caminhos, modelos e soluções, mas ainda estão fragmentados e desconectados. Não existe visibilidade desse "conjunto" como força. Aparecem na mídia de forma isolada, sem constituir "redes".

Esse novo precariado produtivo luta para obter o "copyright" sobre sua própria produção cultural e imagem, sabendo que o agenciamento entre as diferentes esferas (favelas, universidades, movimentos, Estado) pode apontar para uma rede mais ampla de parcerias produtivas e profundamente transformadora da cultura urbana brasileira.

\section{PERIFERIA GLOBAL}

As mudanças que apontamos aparecem com grande visibilidade em cidades como o Rio de Janeiro, território em disputa. A cidade que sempre foi uma meta-narrativa sobre o Brasil passa por profundas transformações nos últimos anos que a colocam no centro do capitalismo 2.0, cognitivo, afetivo e comunicacional. 
Rio, a "cidade beta global “, está no centro de uma disputa simbólica. A passagem do Brasil fordista, nacional-desenvolvimentista para a periferia global em que as bordas invadem o centro e que tem que se reinventar não pela falta e nem pelo negativo (violência, pobreza, crise da cidade), mas pela potência.

Duas mega operadoras simbólicas atuam nesse imaginário carioca: CUFA (Central Única das Favelas) com uma rede de atividades extensa em todo o Brasil e AfroReggae. Duas das mais bem sucedidas experiências de transmutação simbólica da cidade, capazes de juntar numa mesa de negociação ex-traficantes, polícia, governo, banqueiros, mídia e universidade.

Com estratégias intuitivas e paradoxais são experiências de transição entre o "movimento", a narcocultura da favela e do tráfico, e os movimentos sociais e culturais, apontando para uma nova forma de "corporação social" que vai "hackeando" o discurso do social e do cultural das empresas, dos governos, da mídia. "Hackeando" e sendo usados pelas corporações, mas inventando, errando e acertando, criando condições de possibilidade para o surgimento de novos movimentos e atores.

São apenas o lado mais visível (que alguns desqualificam como "king ONGs") de uma mutação subjetiva que se espalha por centenas de coletivos, Pontos de Cultura, produtores culturais, Agências como a "Redes para a Juventude", "Observatórios" de favelas, djs, formadores livres, agitadores, outros sujeitos do discurso que tomam posse da cidade.

E a favela surge como "capital simbólico" e "riqueza" das cidades e especificamente do Rio, ou ainda como "commodities". Não mais os pobres assujeitados e "excluídos" de certo imaginário e discurso, mas uma ciberperiferia, da riqueza da pobreza (disputadas pela Nike, pela TV Globo, pelo Estado) que transforma as favelas, quilombos urbanos conectados, em laboratórios de produção subjetiva.

A carne negra das favelas, os corpos potentes e desejantes, a cooperação sem mando, inventando espaços e tempo outros (na rua, bailes, lan houses, lajes) estão sujeitas a todo tipo de apropriação, exatamente como qualquer um de nós.

É que as favelas não são as fábricas de pobreza, são o maior capital nas bolsas de valores simbólicos do Rio de Janeiro e do país, pois converteram as forças hostis máximas (pobreza, violência, Estado de exceção) em processo de criação e invenção cultural.

O Rio de Janeiro é um termômetro da difícil e paradoxal tarefa de calibrar essa euforia pós-Lula ${ }^{2}$, do presidente-Macunaima que turbinou a potência das periferias e ao mesmo tempo, com a entrada do Brasil na disputa simbólica global e no cerne do capitalismo cognitivo, fez surgir os "gestores de gente", os gestores de subjetividade que revertem e monetizam a potência das favelas e periferias para o turismo, para as corporações, bancos e agenciadores da "economia criativa" e para o consumo.

Mas a construção desse outro comum, o repúdio da guerra contra os pobres (remoções, criminalização e repressão), a força da periferia se impõe de forma incontornável. Fenômenos culturais emergem, como os garotos e garotas da periferia que se inventam como dançarinos, colocando toda sua energia e intensidade nas disputas pelos

\footnotetext{
${ }^{2}$ Ex-presidente da República Luis Inácio da Silva, Lula que criou o bolsa-família e produziu a maior mobilidade social das últimas décadas no Brasil, tirando 30 milhões de brasileiros da faixa da miséria e criando uma $\mathrm{n}$ "nova classe média".
} 
becos, lajes, praças das favelas e compartilhando e inventando coreografias mirabolantes para a "Batalha do Passinho"3 aprendidas nas ruas ou utilizando o You Tube e vídeos postados na Internet.

Estamos assistindo uma ressignificação de valores quando ouvimos um funk composto e cantado por mulheres que transforma o discurso sobre "cachorras" e "popozudas"4 em reivindicação neofeminista sobre a posse do seu corpo e o comportamento sexual libertário e desabusado da periferia.

A mudança de comportamento sexual e postura social também pode ser vista entre os meninos da periferia. O grupo de música “Os Hawaianos”, por exemplo, é composto de meninos negro-louros ${ }^{5}$ que rebolam até o chão, inventam gírias, e criam um estilo próprio de estar no mundo, uma inteligência popular brasileira que reinventa a antropofagia, o Brasil Canibal, versão 2.0, local, global, fabulando um novo "mapa mundi do Brasil”, um devirmundo do Brasil e simultaneamente, um devir-Brasil do mundo.

Quando entendemos que as favelas são parte da cidade entendemos também que se tratam de formações históricas, que as favelas serão vistas um dia como as cidadelas da Idade Média. Arquivos, ambientes vivos de um momento etapa do capitalismo. Vidas-territórios que estão explodindo as fronteiras e podem tomar conta da cidade como um todo, com suas invenções. Favelania. Cidade-Favela, pois como diz José Júnior do Grupo Cultural AfroReggae no Brasil “a elite é que está num gueto".

O Rio de Janeiro (e outros grandes centros no Brasil) está em disputa. A cidade é disputada pelo tráfico de drogas, pelo Estado que busca retomar territórios ocupados pelo tráfico através das UPPs (Unidade de Polícia Pacificadora), pelas milícias (forças para-militares que "vendem” segurança e serviços), pela especulação imobiliária, de olho na "remoção" dos moradores pobres dos pontos turísticos da cidade. A cidade também é disputada por todos os tipos de corporações, as vésperas de dois mega eventos globais, a Copa do Mundo de Futebol em 2014 e os Jogos Olímpicos em 2016, que acontecem no Brasil e no Rio de Janeiro e em e que tem provocado (com a especulação imobiliária, remoções dos mais pobres do cinturão turístico, obras de intervenção em favelas e bairros pobres) um violento processo de redesenho e reordenação do território urbano.

\section{FORMAÇÃO LIVRE E EM FLUXO}

Dentro desse contexto, as linhas de fuga e resistência passam por uma articulação das bordas, de movimentos culturais e sociais que se associam a partir de causas e a partir da produção cultural e que disputam a mídia e a formação da opinião pública, construindo novas narrativas em torno dos territórios e das cidades.

Muitas dessas iniciativas e experiências em curso criam sua própria metodologia de formação: midialivristas, pedagogia Griô, pedagogia quilombola, processos de apropriação das tecnologias pelas culturas populares e tradicionais (indígenas, ribeirinhos, caboclos, etc.), produção cultural e de conhecimentos vindas das periferias brasileiras e das "bordas", apontando para a emergência de uma cultura popular digital. Parte dessa

\footnotetext{
${ }^{3}$ Estilo de dança que se popularizou nas favelas do Rio de Janeiro que combina coreografias do funk, com gestos e passos de diferentes estilos de dança e gêneros musicais. Os dançarinos de funk, são muito jovens, de favelas e bairros pobres do Rio de Janeiro, e utilizam o YouTube para desafios através dos vídeos e encontros presenciais, chamados de "batalhas".

${ }^{4}$ Formas pejorativas das letras de funk se referirem as mulheres sexualmente liberadas e exuberantes.

${ }^{5}$ Meninos negros que pintam o cabelo de louro ou descolorem os cabelos imitando seus ídolos do futebol.
} 
mutação mais ampla em que a cultura se torna central na produção do conhecimento e na constituição de uma nova economia.

Processos de formação, resultados dos fazeres e práticas nos mais diferentes campos: audiovisual, teatro, música, dança, multimídia, conectando e tornando indissociáveis a vida e trabalho desses agentes formadores.

Efervescência e diversidade que podemos encontrar no "Programa Cultura Viva" do Ministério da Cultura do Brasil que se propôs a pensar de forma pioneira e como política pública esses novos arranjos: cultura viva, economia viva, dando visibilidade, conceituando e apontando para o potencial inovador desses processos. E ampliando o próprio conceito de cultura usado nas políticas públicas, para além da produção da chamada "indústria cultural", com uma perspectiva antropológica de cultura que inclui o modo de ser e estar de grupos os mais singulares.

Dentro dessas dinâmicas culturais destacamos os novos processos formativos. Qual o lugar da educação e da formação numa sociedade em que os dispositivos tecnológicos de criação, produção, difusão são atravessados por uma forte dinâmica colaborativa, livre, aberta e baseada em ação direta? E que coloca em xeque os intermediários clássicos: escola, universidade, professores e os certificadores dos saberes?

$\mathrm{Na}$ passagem do capitalismo fordista para o pós-fordista (imaterial, cognitivo, comunicacional), os processos de produção cultural exigem novos modelos de produção do conhecimento, experiências de formação livre, vivências, vidas-linguagens que explodem a "fábrica". O novo ciclo de produção na música, no audiovisual, o midialivrismo, crise das gravadoras, editoras, a crise dos intermediários e atravessadores, a crise do pensamento copyright exige uma nova deriva formativa.

É que a fábrica/Matrix se desregulou, a divisão de saberes e disciplinas estanques que refletia o modelo industrial do século XIX, a linha de montagem com setores isolados e independentes um do outro, se tornou obsoleta, mas ainda atuante: fabricação pela disciplina ou pelo controle de "corpos dóceis".

Vistas como espaços de "encarceramento" (sejam reais ou virtuais) e de poder sobre a vida, é difícil não posicionar a Escola tradicional no mesmo paradigma disciplinar que regia fábricas-hospitais-prisões (como apontou Michel Foucault) ou no mesmo modelo de controle da vida, assujeitamento dos corpos e produção de desejos, que caracterizam o "biopoder" (poder sobre a vida).

\section{VIDA-TRABALHO-FORMAÇÃO-EXPRESSÃO}

A questão contemporânea é que toda a sociedade se tornou formativa. A cidade e as redes são o próprio ambiente cognitivo (a cidade é a nova "fábrica" como diz Antonio Negri). O tempo do trabalho se confunde com o tempo da vida (não mais o trabalho morto automatizado, mas o trabalho-vivo, a vida-trabalho). Nesse contexto a Escola não deveria mais formar para a vida, a Escola torna-se a própria vida, se confunde com ela.

É por isso que vemos uma explosão de iniciativas de educação não formal, escolas livres, universidades livres e uma demanda por formação nos Pontos de Cultura e Pontos de Mídia, tendo como base a autonomia e liberdade como dois princípios para uma revolução/mutação em fluxo, que já está em andamento. 
O desafio é como dar visibilidade e reconhecer esse potencial formador e responder a demanda por formação dos coletivos, comunidades, diferentes tipos de organizações com suas dinâmicas e processos próprios. Experimentar e sistematizar as novas formas de visibilidade partilha e certificações dos saberes.

\section{CIRCUITO CULTURAL E MOVIMENTO SOCIAL}

Nesse sentido destacamos ainda as experiências formativas do Circuito Fora do Eixo (que mobiliza uma rede de coletivos de cultura com cerca de 3 mil jovens em todo o Brasil) e que criou a sua própria "Universidade Fora do Eixo“ (UniFdE), um processo de formação aberto e em fluxo, propondo compartilhar e sistematizar suas metodologias de formação: imersões, vivências, observatórios, oficinas, programas on line de TV/Pós-TV; cartilhas; colunas/caravanas de carro/ônibus que rodam territorialmente por todo o país; etc.

Com uma forte experiência midialivrista e midiativista, o Fora do Eixo é uma das referências em relação aos modos de transformar a precariedade, a fragmentação e atomização dos coletivos, em um circuito integrado e descentralizado, que tem como base de sustentação uma cultura e economia em rede distribuída.

Trata-se de uma proposta singular e bem sucedida de simultaneidade dos processos de realização, experimentação, formação, em que todas as ações do circuito se tornam metodologias potenciais de formação livre, a serem replicadas e compartilhadas e que lança mão de diferentes estratégias de sustentabilidade, tendo como base, os ativos do próprio circuito (tempo livre, força de trabalho, domínio das linguagens midiáticas e narrativas multimídias).

Ao fomentar e organizar circuitos territoriais e virtuais (de música, audiovisual, palco, letras, mídias, redes de formação política), ao criar experiências de vidas compartilhadas e espaços de convivência comunitárias (com caixas coletivos e um novo comunitarismo), ao criar moedas e bancos de tempo, economia viva, a experiência Fora do Eixo transborda as fronteiras vida/educação, vida/trabalho, numa deriva experimental em que tudo é "laboratório", tudo é formação. O processo formativo, seu mapeamento e sistematização não "prepara" para a vida, é a própria vida se experimentando e potencializando.

\section{ECONOMIA DA VIDA}

A ideia de uma "economia da vida" ganha corpo no Brasil a partir de múltiplas experiências. Para além do debate de uma "renda mínima universal", horizonte das novas lutas do precariado cognitivo, podemos destacar as experiências das moedas complementares, moedas sociais ou solidárias e o pensamento da economia solidária e das cooperativas. Entre outras formas, de potencialização da autonomia dos coletivos e invenção de mundos.

Mais uma vez apontamos uma dessas experiências inspiradoras: a do "Caixa Coletivo" (ou Banco do Comum), realizada pelo Fora do Eixo. Quando cerca de 3 mil jovens de todo o Brasil nas cidades do interior e/ou capitais revertem seu tempo e vida para um projeto Comum com um Caixa Coletivo único que paga comida, roupa e casa coletiva, sem salário individual, mas autonomia para retirarem do Comum o que precisarem, abandonam seus "empregos escravos" ou precários na mídia tradicional, na produtora comercial, nas agências de publicidade, ou 
qualquer emprego fordista e tem que inventar sua própria ocupação. Tem seu tempo e vida liberados, produzidos a partir de uma outra lógica distinta e comunitária.

Trata-se da produção dos mundos novos. A experiência de um básico assegurado muda a lógica da produção cultural. É "devolvido" o tempo do Comum que nos é roubado pelo capital, pelo Estado, pela normopatia (pelas obrigações, pela burocracia) quando temos que "vender" nossas habilidades, comunicação e afetos para o "trabalho morto".

A experiência do Caixa Coletivo aponta para uma radicalização do modelo de compartilhamento:

Uma síntese do Caixa Coletivo está no ato de cada participante trazer todos os seus recursos disponíveis, tangíveis e intangíveis, à disposição para as decisões coletivas. Dedicação, estímulo, articulação, mobilização, expertise, paciência, agilidade, dinheiro, cartão, cheque, nome, celular, roupas, bens, produtos, contatos, planos, trabalho, conflitos e sonhos sob gestão integral de cada um, são vistos como recursos do caixa coletivo. Todos devem ser colocados "na roda" pra serem utilizados de forma compartilhada, como força motriz e elementares pra sustentar qualquer passo decidido pelo grupo. $\left(\right.$ LENZA, 2013) ${ }^{6}$

É essa disponibilidade radical e tempo livre e autônomo investido no Comum que está na gênese das revoluções do precariado cognitivo. Quem já "perdeu" tudo ou abriu mão de família normopata, salário certo, titulação universitária, para investir toda sua vida em um projeto coletivo, pode tudo.

Novos desafios aparecem nesse modelo de compartilhamento radical e fundo comum (seguridade, dificuldades de gestão partilhada, horizontalidade das relações), mas ter o tempo livre (pago coletivamente), não ter que "vender" seu tempo por comida, roupa e casa é ter uma base mínima de vida sustentável e não se confunde com "trabalhar de graça", nem se trata de uma "renda" ou "bolsa" mínimas. Trata-se de uma outra economia e horizonte de pactuação coletiva para a invenção de mundos. O Banco do Comum pode ser essa base para uma nova "economia da vida".

Nesse contexto das redes e coletivos de produção cultural, podemos mencionar ainda as experiências midialivristas (de formação pela mídia e para as mídias) que inovam ao simplesmente desconfigurarem os espaços tradicionais de fala: a Escola Popular de Comunicação Critica da Maré (ESPOCC), a Escola de Hip Hop do movimento Enraizados, no Rio de Janeiro, a Agência Redes para a Juventude, o projeto Cinema.

Os diferentes coletivos e movimentos que convertem a carência/falta/precariedade em potência, ressignificando os territórios vulneráveis, a favela, as periferias, disputando narrativas e inventando suas próprias metodologias de formação.

O entendimento que a comunicação e a mídia deixaram de ser "ferramentas" e se tornaram a própria forma de organização dos movimentos culturais e sociais se expressa de forma transversal nos diferentes projetos e missões dos pontos e coletivos e de forma mais explicita nos projetos de comunicação e midiativismo. ${ }^{7}$

Trata-se de mobilizar a todos diretamente em um processo intensivo e midiático de formação política que ativa e desloca os lugares de poder/saber. A formação política surge, assim como horizonte e missão de muitos

\footnotetext{
${ }^{6}$ Apresentação Caixa Coletivo 2013, Lenissa Lenza, texto inédito.

${ }^{7}$ Proposta encontrada em diferentes projetos e coletivos: Agência Pública, Coletivo Palafita, Jornalismo B, Voz da Comunidade etc.
} 
grupos, e a demanda por um aprofundamento e continuidade nessa formação também são vocalizadas nas propostas de diferentes coletivos.

A ideia que a produção de conhecimento deva ser livre e aberta, gratuita, (utilizando licenças flexíveis, Criativa Comum, Recursos Educacionais Abertos/REA) é decisiva nesse novo paradigma. Nesse sentido políticas públicas como banda larga gratuita, o Marco Civil para a Internet ou a Reforma da Lei do Direito Autoral _ descriminalizando as práticas do compartilhamento de arquivos, cópias, exibições de filmes para uso educacional, cultural são a base da revolução dos "commons", dos bens comuns partilháveis e da emergência de uma intelectualidade de massa.

Daí o estímulo decisivo a pesquisas em processo (work in progress) abertas na rede e utilizando linguagem Wiki, construção de repositórios públicos e gratuitos de dados e conteúdos, servidores públicos e plataformas, disseminação das WebTVs, transmissão ao vivo de conteúdos audiovisuais os mais heterogêneos.

Os princípios da Cultura Livre e da Cultura Digital são outra plataforma transversal, condição para a sustentabilidade e potencialização do campo midialivrista e surgem pontualmente ou como missão de diferentes grupos que trabalham com a apropriação tecnológica. ${ }^{8}$

Essas são também algumas das condições de uma wiki-escola ou wiki-universidade, Universidade P2P ou formação aberta, em que o processo de ensino-aprendizado e a produção dos conteúdos envolvem em diferentes níveis todos os participantes e a própria formação dos educadores/formadores é baseada na produção de conteúdo para os ambientes colaborativos e ferramentas livres.

Outro aspecto importante é a atenção para as linguagens, narrativas, que deixam de ser questões acessórias e junto com a apropriação tecnológica surge como campo de disputa e ação de muitos coletivos. Arte contemporânea, performances, ações politico-midiáticas que encaram a estética como indissociável de um campo de expressão e intervenção política, como ampliação de repertório e posse das diferentes linguagens da arte contemporânea.

\section{FUTUROS ALTERNATIVOS}

No filme Minority Report, mutante sensitivo-sensoriais alucinam o futuro. Os PreCogs (criação de Philip K. Dick), considerados "idiotas", “doentes" e "drogados" pelo sistema, têm o poder de premonição do futuro, vislumbram cenas, indícios, fragmentos e sinais de possíveis crimes. Uma premonição paradoxal que seria totalmente inútil se não existisse a possibilidade de alterar o futuro. Criar realidades alternativas.

A ideia de futuros múltiplos começa a se formar no Brasil, com a articulação entre os movimentos sociais, culturais, coletivos, redes, midialivristas, Pontos de Cultura, minorias e maiorias em torno de movimentos transversais (Marchas da Liberdade, em São Paulo e em 70 cidades do país, Marcha das Vadias, Bicicletadas, Marcha da Maconha, em 2011; Existe Amor em SP em 2012, etc.) conectando lutas locais e globais, exigindo liberdade de expressão, cultura livre, combate ao preconceito e posse da cidade e dos espaços públicos.

São os nossos PreCogs, uma nova "classe" transversal, o Precariado Cognitivo, precários sensitivos que alucinam/criam futuros.

${ }^{8}$ Coletivo Digital, Iconoclassistas, ecologias, entre outros coletivos e redes. 
O precariado da cultura junta camelôs, sem-teto, removidos, agentes da economia informal, garotos de classe média, diplomados autônomos desempregados, todos que tem que inventar seu próprio trabalho, os ecoativistas, os militantes pela legalização das drogas, homoafetivos, os negros, as periferias, os que andam por terreiros e quilombos ou por terras digitais. Essa é a nova "classe" do capitalismo cognitivo e a força-motriz e de reinvenção da dobra brasileira no contexto global. 